\title{
Impacts of Different Parameters on Spray Cooling of Copper Alloy B14
}

\author{
Kabbir Ali ${ }^{1,2^{*}}$, Riffat Amna ${ }^{3}$, Muhammad Irfan Malik ${ }^{4}$, Sami Ibn Shamsah ${ }^{5}$, Kiseong Kim² \\ ${ }^{1}$ Institute of Fluid Power and Thermodynamics, Otto von Guericke University, Magdeburg 39106, Germany \\ ${ }^{2}$ Department of Mechanical Design Engineering, Chonnam National University, Yeosu 59626, South Korea \\ ${ }^{3}$ Department of Applied Chemical Engineering, Kyungpook National University, Daegu 41566, South Korea \\ ${ }^{4}$ Department of Chemical Engineering, University of Hafr Al Batin, Hafr Al Batin 31991, Saudi Arabia \\ ${ }^{5}$ Department of Mechanical Engineering, University of Hafr Al Batin, Hafr Al Batin 31991, Saudi Arabia
}

Corresponding Author Email: ali_kabbir@ hotmail.com

https://doi.org/10.18280/acsm.430501

Received: 5 June 2019

Accepted: 10 August 2019

\section{Keywords:}

$1 D$ model, surface roughness, spray nozzle, full jet nozzle, water effect

\begin{abstract}
This paper attempts to determine how the cooling effect of copper alloy B14 varies with roughness, type of water and type of nozzle. Several experiments were performed on $5 \mathrm{~mm}$ thick copper alloy B14 plates with different combinations of the said parameters. The plates with smooth and rough surfaces were heated up to the $520{ }^{\circ} \mathrm{C}$. Either tap or distilled water was used as coolant with constant volumetric flow rate, $1.2 \mathrm{~L} / \mathrm{min}$. Two types of nozzle were tested, namely, spray nozzle (460.404) and full jet nozzle (544.400). The results of the cooling rate were analyzed on the $1 \mathrm{D}$ model. It is observed that distilled water led to a slightly faster cooling rate than tap water, due to oxidation on the copper alloy; rough surface caused fast heat transfer compared to the smooth surface; the domination of nucleate boiling regime was observed in the case of full jet nozzle, as compared to the case of to the spray nozzle, because the full jet nozzle can prevent vapor formation on the material; the spray nozzle covered a larger wetting front area than the full jet nozzle. The results were verified through experiments on the two types of nozzles.
\end{abstract}

\section{INTRODUCTION}

Non-uniform heat extraction under the continuous casting process causes cracks and distortions on the surface of metals. The accurate estimation of heat transfer coefficient $(\mathrm{h})$ of alloy surface is necessary to predict the cracks during the metal casting process. Generally, the heat transfer of ingot surface classifies into the three different regions. The $1^{\text {st }}$ region is related to the surface of the mold, which is the direct contact region and second region related to the air gap, which is between the two surfaces and the falling water film region. In the steady-state DC casting operation process, primary cooling dissipates twenty percent of the heat, and about eighty percent is extracted by secondary cooling using water. Therefore, the coolant/water strikes on the hot material's surface and develops a falling film on its surface in the secondary cooling zone. The water film moves down on the hot surface and swept away bubbles. The thin water vapor layer containing low thermal conductivity, which resists the heat flows from the hot surface, behave like as an insulator. Comparatively, the heat transfer rate in the film boiling region is low. When the surface temperature of ingot goes down to Leidenfrost temperature, the vapor film starts to disappear and begins the transition and nucleates boiling while the coolant moves down on the ingot's surface, a thin wetting front develops. It completely separates the nucleates and film boiling regions and also proceed against the water flow direction continuously with a velocity known as wetting front velocity [1-6]. In a recent development, cooling techniques which are used to extract more heat have received much attention because of different problems in modern industrial and technological applications. These applications include electronics components cooling, generation of nuclear power, high-power lasers utilization, and advanced processes of metallurgy. Continuous casting processes in the metallurgical industry using the spray cooling technique for quenching of different metals and cooling of metal alloy strips. This technique is also used in the nuclear reactor [7]. In industry, the use of coolant such as water for cooling of heated material is inevitable when high HF is required, e.g., in nuclear safety and alloys thermal processing in the steel industry. Pool boiling, liquid jets or sprays impingement are included in cooling processes. Liquid jets and pool boiling are extensively utilized in the steel industry. Their high dissipation rate is the critical factor of their utilization in the steel industry, but sometimes it is not able to ensure uniform cooling. Due to this reason, metallurgical phase suffers many defaults in its homogeneity. Spray usage seems attractive for several reasons: For less water consumption at the same efficiency in terms of heat transfer can achieve a better spatial uniformity of the cooling. Moreover, for less water consumption require low energy for recycling and pumping of cooling water, and an increase is observed in the whole energy efficiency of the process [8].

As compared to other cooling techniques like air cooling and cooling of the heat pipe, spray cooling shows high heat flux, less surface superheats, and less coolant mass flow rate. It is utilized in different processes like quenching of metals, laser system cooling, microelectronics cooling, and cooling of high-power electronics [9]. Film boiling, Transition boiling, Nucleate boiling and forced convection are important heat transfer mechanism steps of the spray cooling and the complex heat transfer phenomena have resulted in high heat flux 
compared to the pool boiling by using the same liquid [10-12]. For example, after utilizing water as a coolant, the critical heat flux (CHF) of the pool boiling and the spray cooling are approximately $120 \mathrm{~W} / \mathrm{cm}^{2}$ and $1000 \mathrm{~W} / \mathrm{cm}^{2}$. Hongbo Xu et al. [9] specify that heat transfer coefficient increased with respect to the increase in the mass flow rate of coolant. At $6.9 \mathrm{~kg} / \mathrm{h}$ mass flow rate, the heat transfer coefficient was up to 25,373 $\mathrm{W} /\left(\mathrm{m}^{2}{ }^{\circ} \mathrm{C}\right)$ at the surface temperature of $57.3^{\circ} \mathrm{C}$. The heat flux increases gradually with surface temperature and decreases right away after CHF occurs, by using spray cooling with pure water. However, on the other way, heat flux shows a sharp increase to its CHF by using surfactant solution and remains constant with a relatively wide temperature range [13]. For high heat flux cooling applications, spray, and jet impingement is best.

Pereira et al. [13] specified that as compared to jets, sprays provide area-averaged heat transfer coefficients, but they require a smaller coolant flow rate. Sleiti and Kapat [14] listed the same results. Similar results have been presented using a jet nozzle with single spray data [15-16]. They reported that sprays offer more cooling due to the unsteady boundary layer, produced by droplet impact and also because of evaporation. In reverse to micro-jets, Fabbri et al. [17] indicate that sprays need a high ratio of pumping power to heat removal rate. However, compared to micro-jets, sprays offer more cooling performance. Mzad and Khelif [18] presented that by increasing the coolant pressure, the heat transfer coefficient increases.

In this research work, fast and uniform cooling process are analyzed on copper alloy by using spray and full jet nozzle. The purpose of this study is how to enhance the uniform cooling by using different parameters such as type of water, surface, and nozzle.

For this purpose, many experiments have been performed on Copper alloy B14. Copper plates of $5 \mathrm{~mm}$ thickness with smooth and rough surfaces heated up to the $520{ }^{\circ} \mathrm{C}$. In these experimental works, two types of water such as tap and distilled water are utilized as a coolant with constant volumetric flow rate, $1.2 \mathrm{l} / \mathrm{min}$. Two kinds of nozzle such as spray nozzle 460.404 and full jet nozzle 544.400, were used, which are spray nozzle and full jet nozzle respectively. The 1D model is utilized to analyze the results of the cooling rate.

\section{EXPERIMENTAL SETUP AND PROCEDURE}

Figure 1 represents schematic experimental arrangements.
The experimental setup has been arranged to study the influence of important parameters on the cooling process of smooth and rough metal samples. It includes furnace, a cooling chamber, full jet nozzle (544.400) and a spray nozzle (460.404). Infrared camera FLIR SC3000 has also used to measure the temperatures on the material, and GoPro video camera was used to record the wetting front phenomena. Metallic sheet samples of the copper alloy used in the experiments and dimensions represented in Table 1. First, copper plates with real and smooth surfaces heated in the furnace at $520{ }^{\circ} \mathrm{C}$. The temperature could be adjustable depending on requirements. For example, a steel plate is heated up to $800{ }^{\circ} \mathrm{C}$, but the temperature cannot exceed more than $520{ }^{\circ} \mathrm{C}$ in copper alloy case. After that, the sample placed into the cooling chamber where the metal sheet is sprayed from the front by a spray nozzle and full jet nozzle, depending on the method of quenching. Wetting front progress has been recorded and measured with a video camera. According to the current objective of the experiments, the water flow rate and water pressure are adjusted. Sheet's front side is smooth/rough side, but the other side is painted with black graphite paint to achieve an emissivity of 0.94 . An Infrared (IR) camera is used to measure the surface temperature of the painted side; It has the capability of measuring the temperature at every pixel with a frequency of $150 \mathrm{~Hz}$ within a window of $240 \times 80$ pixels.

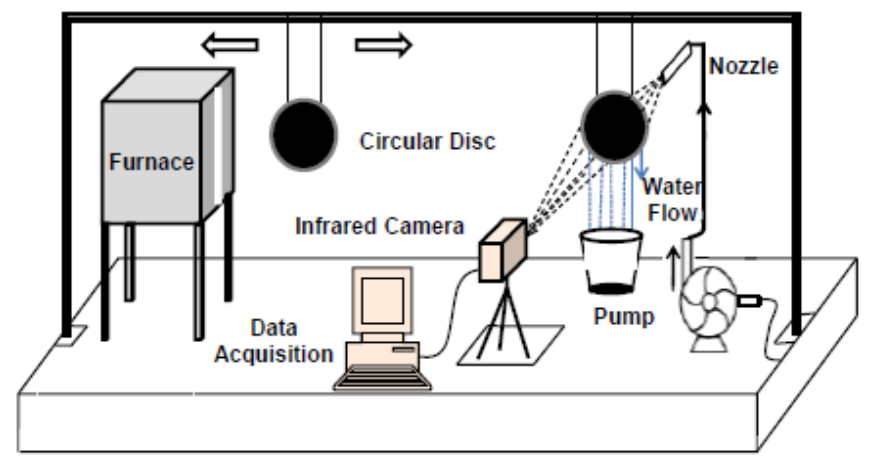

Figure 1. Experimental setup

Table 1. Material dimensions

\begin{tabular}{|c|c|}
\hline Copper alloy B14 dimensions & mm \\
\hline Length & 250 \\
\hline Width & 250 \\
\hline Thickness & 5 \\
\hline
\end{tabular}

Table 2. Operatinng parameters

\begin{tabular}{|c|c|c|c|c|c|c|c|c|}
\hline $\begin{array}{c}\text { Metal } \\
\text { sheet }\end{array}$ & $\begin{array}{c}\text { Thickness } \\
(\mathbf{m m})\end{array}$ & $\begin{array}{c}\text { Volumetric flow } \\
\text { rate (l/mint) }\end{array}$ & $\begin{array}{c}\text { Initial } \\
\text { temperature }\left({ }^{\circ} \mathrm{C}\right)\end{array}$ & Nozzle & $\begin{array}{l}\text { Spacing } \\
(\mathbf{H}) \mathrm{mm}\end{array}$ & Surface & Water & $\begin{array}{c}\text { No of } \\
\text { measurements }\end{array}$ \\
\hline \multirow{8}{*}{$\begin{array}{c}\text { Copper } \\
\text { alloy B14 }\end{array}$} & \multirow{8}{*}{5} & \multirow{8}{*}{1.2} & \multirow{8}{*}{500} & \multirow{4}{*}{$\begin{array}{l}\text { Spray } \\
\text { nozzle }\end{array}$} & 50 & smooth & Tap water & 2 \\
\hline & & & & & 50 & smooth & $\begin{array}{l}\text { Distilled } \\
\text { water }\end{array}$ & 2 \\
\hline & & & & & 50 & $\begin{array}{c}\text { Real/rough surface } \\
(0.25 \mathrm{~mm})\end{array}$ & $\begin{array}{c}\text { Distilled } \\
\text { water }\end{array}$ & 2 \\
\hline & & & & & 50 & $\begin{array}{c}\text { Real/rough surface } \\
(0.25 \mathrm{~mm})\end{array}$ & Tap water & 2 \\
\hline & & & & \multirow{4}{*}{$\begin{array}{l}\text { Full jet } \\
\text { nozzle }\end{array}$} & 50 & smooth & $\begin{array}{l}\text { Distilled } \\
\text { water }\end{array}$ & 2 \\
\hline & & & & & 50 & smooth & Tap water & 2 \\
\hline & & & & & 50 & $\begin{array}{c}\text { Real/rough surface } \\
(0.25 \mathrm{~mm})\end{array}$ & $\begin{array}{l}\text { Distilled } \\
\text { water }\end{array}$ & 2 \\
\hline & & & & & 50 & $\begin{array}{c}\text { Real/rough surface } \\
(0.25 \mathrm{~mm})\end{array}$ & Tap water & 2 \\
\hline
\end{tabular}


The distance between the two consecutive pixels is around $0.9 \mathrm{~mm}$. The experiments are repeated for copper alloy B14 by varying water types and nozzle, represented in Table 2 . The water temperature kept constant such as $\left(18{ }^{\circ} \mathrm{C}\right)$. All the recorded data from the infrared camera stored on the computer. A rectangular shape metal sample used for the cooling purpose. However, it is observed that under the array of jets, water flows parallel to the surface of the plate while the use of a spray nozzle allowed water to flow perpendicular.

\section{ANALYSIS METHOD}

For a simple analysis method, the temperature distribution is assumed to be stationary through the thickness of the metal sample. In addition to that, the heat transfer of the disk with the width $\partial \mathrm{r}$, as shown in Figure 2 measured from the energy balance. This analysis method has been described [19].

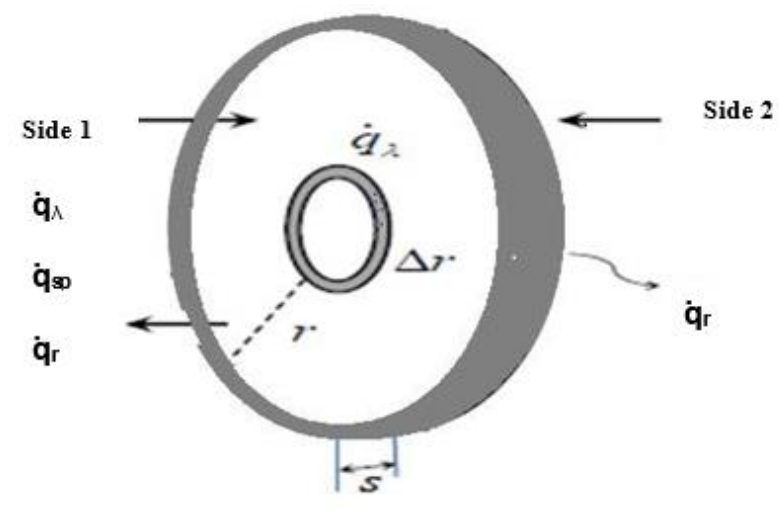

Figure 2. Heat loses during spray quenching

By applying the energy balance:

$$
\dot{Q}_{\lambda, \text { in }}-\dot{Q}_{\lambda, \text { out }}-\dot{Q}_{c}=\frac{d H}{d t}
$$

$\dot{Q}_{\lambda, \text { in }}$ : Conductive heat transfer

$$
\begin{aligned}
& \dot{Q}_{\lambda, \text { in }}=2 . \text { M.r.s.q } \mathrm{r} \\
& \dot{Q}_{\lambda, \text { out }}=2 \text {.П.r.s.q } \mathrm{r}+\frac{\partial}{\partial r}(\text { 2.П.r.s.q } \mathrm{r}) \mathrm{dr} \\
& \dot{Q}_{c}=2 \text {. П.r.q }
\end{aligned}
$$

\section{$\dot{Q}_{c}$ : Convective heat transfer}

The change of the enthalpy in the volume element is calculated by

$$
\frac{\mathrm{dH}}{\mathrm{dt}}=\rho \cdot \mathrm{C}_{\mathrm{p}} \cdot\left(2 \cdot \text {. I.r s.dr) } \frac{\mathrm{dT}}{\mathrm{dt}}\right.
$$

S: Thickness of the material

$\frac{\mathrm{dT}}{\mathrm{dt}}$ : Tempeature gradient

By putting values of Eqns. (1), (2), (3) and (4) in main equation and simplifying equation, we have

$$
-\frac{1}{r} \cdot \frac{\partial}{\partial r}\left(r \cdot q_{r}\right)-\frac{q_{c}}{s} \cdot=\rho \cdot \mathrm{C}_{\mathrm{p}} \cdot \frac{d T}{d t}
$$

So,

$$
\mathrm{q}_{\mathrm{r}}=-k \cdot \frac{\partial T}{\partial r}
$$

$\mathrm{q}_{\mathrm{r}}$ : Heat flux through conduction

$$
q_{c}=\alpha(\mathrm{Ts}-\mathrm{T} \text { water })
$$

$q_{c}$ : Heat flux through convection

By putting values of Eqns. (7), (8) into Eq. (6) and simplifying the equation,

$$
\alpha\left(\mathrm{T}_{\mathrm{s}}-\mathrm{T}_{\text {water }}\right)=\mathrm{K} . \mathrm{s} \cdot \frac{1}{r} \cdot \frac{\partial}{\partial r}\left(r \cdot \frac{\partial T}{\partial r}\right)-\rho \cdot C_{p} \cdot S \cdot \frac{\partial T}{\partial t}
$$

From above equation, the heat transfer rate can be calculated by the following formulae

$$
\begin{gathered}
\alpha=\frac{\mathrm{K} \cdot \mathrm{s} \cdot \frac{1}{r} \cdot \frac{\partial}{\partial r}\left(r \cdot \frac{\partial T}{\partial r}\right)-\rho \cdot C_{p} \cdot s \cdot \frac{\partial T}{\partial t}}{T_{s-T_{\text {water }}}} \\
\alpha=\frac{\mathrm{K} \cdot \mathrm{s}\left[\frac{1}{r} \cdot \frac{\partial T}{\partial r}+\frac{\partial 2 T}{\partial r^{2}}\right]-\rho \cdot C_{p} \cdot s \cdot \frac{\partial T}{\partial t}}{T_{s-T_{\text {water }}}}
\end{gathered}
$$

Therefore, heat flux is

$$
\mathrm{q}=-\rho \cdot s \cdot \mathrm{C}_{\mathrm{p}} \cdot \frac{d T}{d t}+\mathrm{K} \cdot \mathrm{s}\left[\frac{1}{r} \cdot \frac{\partial T}{\partial r}+\frac{\partial 2 T}{\partial r^{2}}\right]
$$

\section{RESULTS AND DISCUSSION}

\subsection{Water quality effect on the cooling process of the smooth and rough surface of copper alloy}

Tap and distilled water are used to record the cooling process of copper plate B14 for both smooth and real/rough surfaces. Figure 3(a) and 3(b) show the water effect on the cooling process of copper alloy with a flat and uneven surface, respectively. It is observed that cooling rate is a little slower by using tap water. In Figure 3(a), solid line indicates the cooling curve of the first measurement that shows the cooling process is fast, and cooling time is about 2.4 second. On the other side, the film boiling region is very concise, and we can neglect that but nucleate boiling area prevails and maximum heat extracted in this region experienced in both tap and distilled water. The same process has observed on the copper plate with a real/rough surface. Figure 3(b) shows that cooling time is also varying by using tap water, and the cooling process is slower compared to distilled water.

In Figure 3(b), results indicate that the cooling process is little slower using tap water compared to distilled water for a rough surface. It also suggests that cooling curve at radius 1 by using tap water that represents the cooling time is about 1.5 seconds which is approximately 1.2 times slower than the cooling process by using distilled water at the same conditions. Consequently, there is no significant difference in the cooling process by using tap water as well as distilled water in case of copper material. The cooling process by using tap water is slow due to the presence of some metals which can be oxidized at high temperature and make an oxidized layer on the surface which resists the cooling process. 


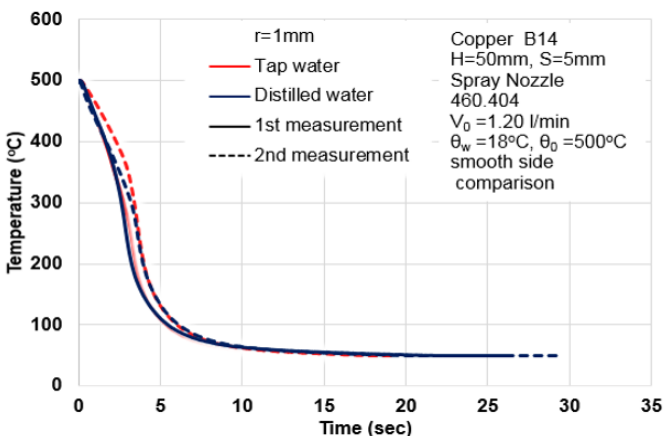

(a) Smooth surface

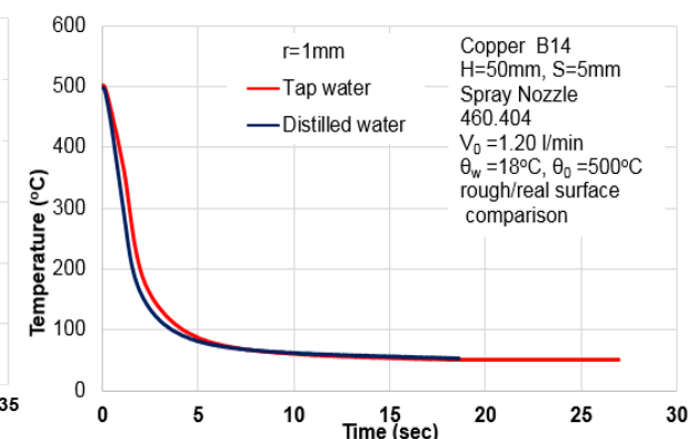

(b) Rough/real surface

Figure 3. Comparison of temperature curves of different measurements for smooth surface and rough/real surface

\subsection{Effect of full jet nozzle on spray cooling by using tap and distilled water}

Figure 4(a) and (b) show the results of the cooling process of $5 \mathrm{~mm}$ thickness of copper alloy by using a full jet nozzle. Figure 4(a) indicates the results by using tap water while Figure 4(b) represents the results by using distilled water at different radius for different measurements. For all the repeated experiments, it was recorded no difference in the cooling curves by using a full jet nozzle.

It indicates that at the starting point, vapor collapses, and vapor film does not prevail on the material and regime of nucleate boiling is dominant in this process. After that, the liquid film develops on the material, and the temperature remains constant. The full jet nozzle plays an essential role in the extraction of more heat in a short time because of high velocity compared to a spray nozzle, and it also prevents salt deposition on the material and shows the same effect after repeating experiments. Additionally, water has the same impact on the cooling process; either used tap water or distilled water for the copper alloy. Figure 4(b) shows the results of distilled water using full jet nozzle. It indicates that cooling time and trend of the curve are approximately similar at the center point like tap water. It is not observed film boing, transition boiling regime by using distilled water in Figure 4(b). It showed rapid cooling phenomena using distilled water. So, it is concluded that a full jet nozzle extracts more heat and shows the same results for all repeating measurements regardless of type of water.

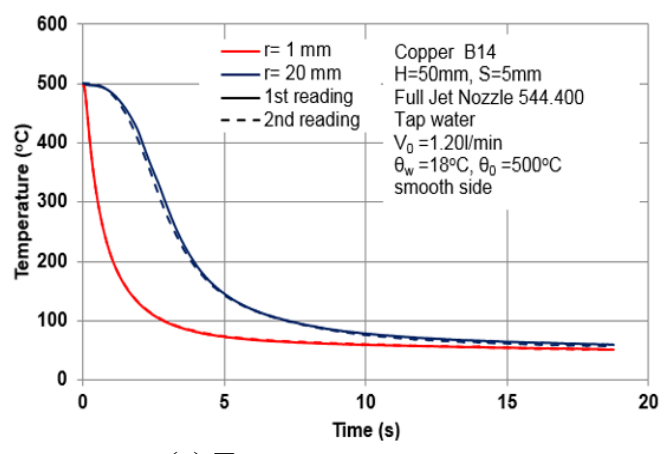

(a) Tap water

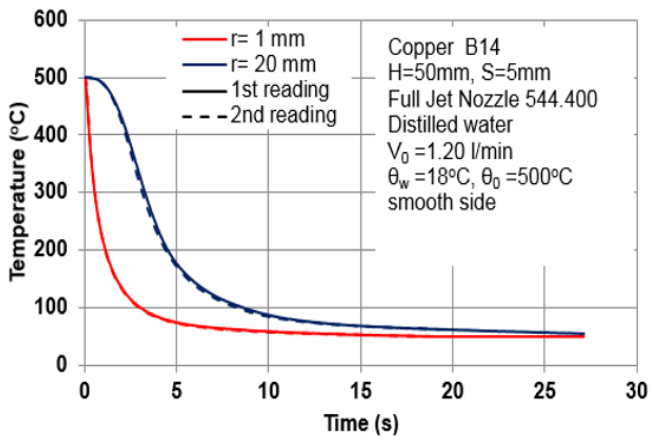

(b) Distilled water

Figure 4. Comparison of temperature curves for different measurements at different radius for tap water and distilled water

Figure 5 shows the result of calculations obtained from cooling test by using full jet nozzle conducted on copper material having thickness $5 \mathrm{~mm}$ at a different radius. The cooling analysis performed at the water volumetric flow rate of $1.2 \mathrm{l} / \mathrm{mint}$ and water temperature $18^{\circ} \mathrm{C}$. Figure 5 shows the absence of the film boiling region at the stagnation point of the jet (i.e., $r=1 \mathrm{~mm}$ ). This observation may be attributed to the high velocity of the cooling fluid, preventing the formation of a stable vapor layer. The heat flux increases with the decrease of the surface temperature to approximately $400^{\circ} \mathrm{C}$. However, after passing the maximum heat flux, it starts decreasing. For the boiling curves far from the impinging jet (i.e., $r=9 \mathrm{~mm}$ ), i.e., in the parallel flow zone, the trend of heat flux curve is same as previous one, but it reaches to a maximum at temperature $300{ }^{\circ} \mathrm{C}$. The full jet nozzle does not support to make a film boiling region, and heat flux abruptly reaches to maximum value than decrease linearly by decreasing the surface temperature.

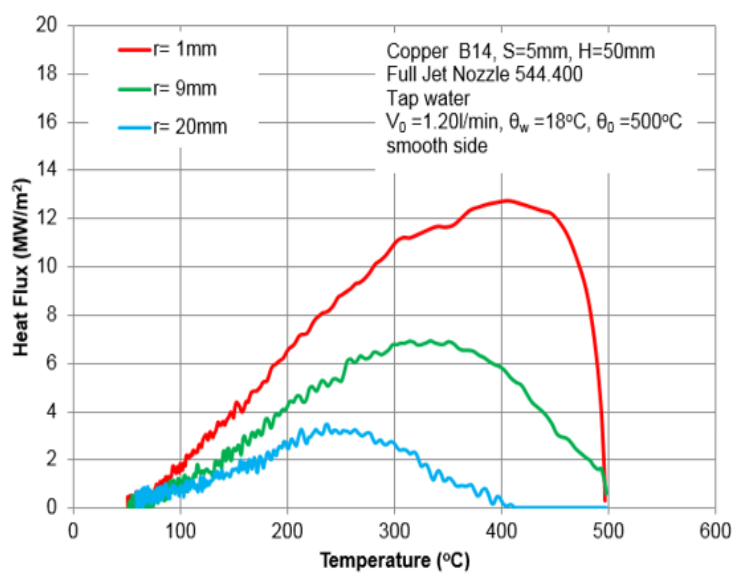

Figure 5. Comparison of heat flux for the smooth side at the different radius 


\subsection{Effect of real surface/surface roughness on heat transfer by using different types of nozzle}

Figure 6(a) and (b) indicate the cooling curves of smooth and rough surfaces by using tap water and distilled water, respectively. Dotted lines on the figures show the effect of roughness on heat transfer. As we can see, that cooling process is faster for rough surface compared to a smooth surface, whether distilled or tap water used. In Figure 6(a), there is no film boiling region; it seems that by using tap water, a rough surface is not able to support the formation of a vapor layer, but it only supports transition as well as the nucleate boiling region in which maximum heat can be extracted. On the other side, the temperature is abruptly reduced in case of roughness and approach to minimum temperature and remains constant. The cooling process is similar in both Figure 6(a) and (b), but only changes are in Leidenfrost temperature.

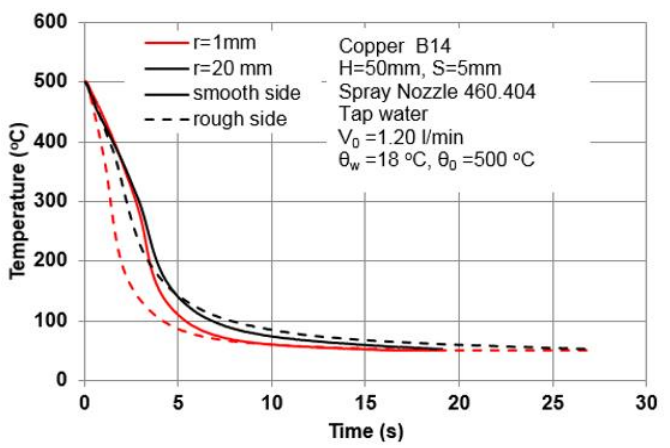

(a) Tap water

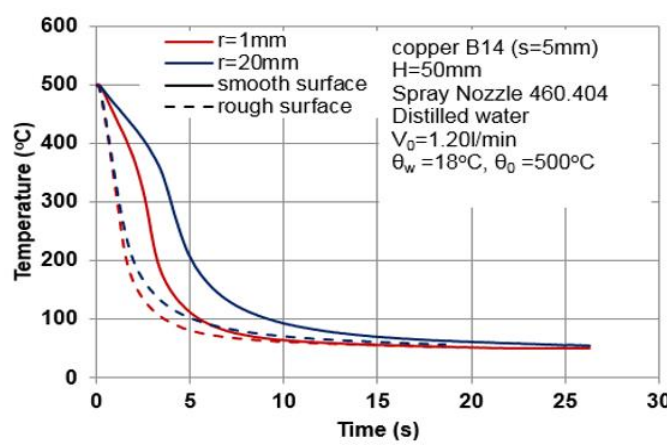

(b) Distilled water

Figure 6. Comparison of temperature curves for the smooth and real surface at different radius for tap water and distilled water using spray nozzle

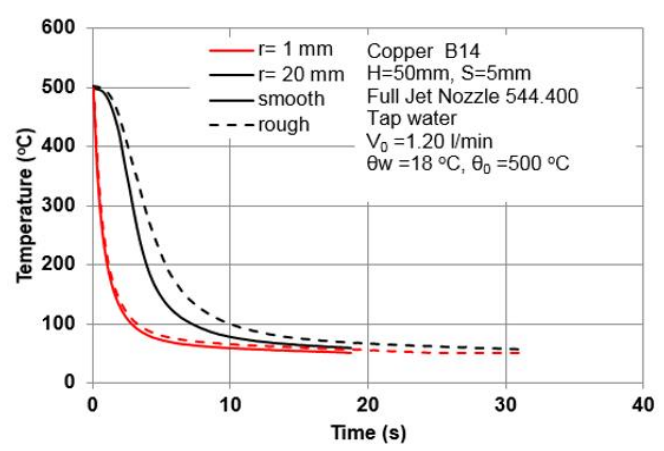

(a) Tap water

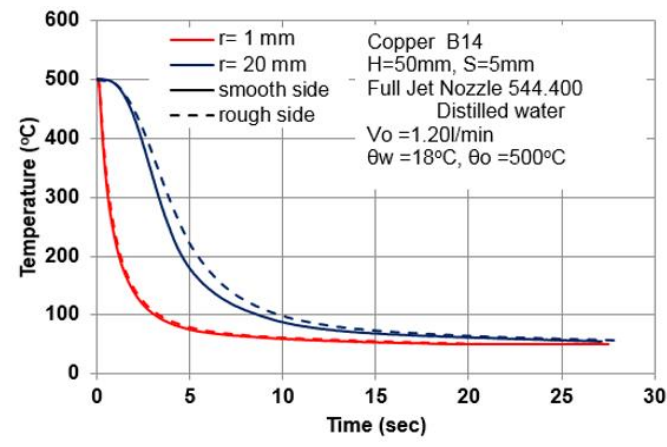

(b) Distilled water

Figure 7. Comparison of temperature curves for the smooth and real surface at different radius for tap water and distilled water using Full jet nozzle

Leidenfrost temperature for the smooth side in case of distilled water is high as compared to tap water because maximum heat is extracted when vapor starts to collapse at high temperature and starts the cooling. It is concluded that cooling is faster in case of surface roughness but results also support this argument that cooling is more rapid by using distilled water compared to tap water in case of copper alloy.

It is also analyzed the impact of rough surface on the heat transfer/cooling rate in case of copper alloy by using tap water and distilled water. Figure 7(a) and (b) indicate the cooling curves of smooth and rough surfaces by using tap and distilled water respectively, in which dotted lines show the effect of real surface on heat transfer.

The cooling process is the same for rough and a smooth surface using a full jet nozzle whether distilled water or tap water was used. In both figures, there is no film boiling region; it seems that a full jet nozzle has very high velocity and cannot support the formation of a vapor layer. It is already described that full jet nozzle only responsible for transition and nucleate boiling irrespective of type of water, surface types. It observed that the cooling process is similar to the center position, and cooling is more rapid at the center by using tap water and distilled water. On the other side, we noticed the cooling process is fast for the smooth surface in contrast to the rough one at the position of $r=20 \mathrm{~mm}$ from the center in both types of water. Full jet nozzle shows the same results whether tap water or distilled water is used. The full jet nozzle also represents similar results for both surfaces such as the smooth and rough surfaces.

\section{CONCLUSIONS}

An experimental analysis has been done to check the impact of the roughness of the surface, quality of water, and type of nozzle on heat transfer of copper alloy B14. There is no significant difference recorded in the cooling process by using tap water as well as distilled water, and rough surface is responsible for extracting more heat by using a spray nozzle as compared to a smooth surface this is because of nucleate boiling region domination in a rough surface. Furthermore, full jet nozzle extracts more heat compared to spray nozzle because full jet nozzle does not support to form a vapor layer on the metal surface which decrease the heat transfer rate. Therefore, full jet nozzle showed the same behavior in the cooling process irrespective the type of water and surface of 
the metal used. For smooth or rough surfaces, cooling curves are the same under the use of full jet nozzle and do not affect the cooling rate.

It concluded that a full jet nozzle had used to extract more heat for both surfaces of metals compared to the spray nozzle. Cooling started at the beginning by using a full jet nozzle rather than the spray nozzle. Similarly, quality of water only effects on cooling rate when using a spray nozzle while cooling rate remained constant under the full jet nozzle.

It is recommended to analyze the effect of salt addition on the spray cooling process and it is also recommended to check the effect of different type of artificial surface roughness on the spray cooling process in the future study.

\section{REFERENCES}

[1] Sengupta, J., Thomas, B.G., Wells, M.A. (2005). The use of water cooling during the continuous casting of steel and aluminium alloys. Metallurgical and Materials $\begin{array}{lll}\text { Transactions } & \text { A, } & 36(1) \text { : }\end{array}$ https://doi.org/10.1007/s11661-005-0151-y

[2] Smakulski, P., Pietrowicz, S. (2016). A review of the capabilities of high heat flux removal by porous materials, micro channels and spray cooling techniques. Appl Thermal Engineering, 104(5): 636-646. https://doi.org/10.1016/j.applthermaleng.2016.05.096

[3] Wen, M., Jang, K., Ho, C. (2014). The characteristics of boiling heat transfer and pressure drop of $\mathrm{R} 600 \mathrm{a}$ in a circular tube with porous inserts. Applied Thermal Engineering, $\quad$ 64(1-2): $\quad 348-357$. https://doi.org/10.1016/j.applthermaleng.2013.12.074

[4] Leong, K.C, Jin, L.W. (2005). An experimental study of heat transfer in oscillating flow through a channel filled with an aluminium foam. International Journal of Heat and Mass Transfer, 48(2): 243-253. https://doi.org/10.1016/j.ijheatmasstransfer.2004.08.025

[5] Agostini, B., Thome, J.R., Fabbri, M., Michel, B., Calmi, D., Kloter, U. (2008). High heat flux flow boiling in silicon multi-micro channels Part $\mathrm{I}$ : Heat transfer characteristics of refrigerant R236fa. International Journal of Heat and Mass Transfer, 51(21-22): 54005414.

https://doi.org/10.1016/j.ijheatmasstransfer.2008.03.006

[6] Bogojevic, D., Sefiane, K., Walton, A.J., Lin, H., Cummins, G., Kenning, D.B.R., Karayiannis, T.G. (2011). Experimental investigation of non-uniform heating effect on flow boiling instabilities in a micro channel-based heat sink. International Journal of Thermal Sciences, 50(3): 309-324. https://doi.org/10.1016/j.ijthermalsci.2010.08.006

[7] Jia, W., Qiu, H.H. (2003). Experimental investigation of droplet dynamics and heat transfer in spray cooling. Experimental Thermal and Fluid Science, 27(7): 829-838. https://doi.org/10.1016/S0894-1777(03)00015-3

[8] Labergue, A., Gradeck, M., Lemoine, F. (2015). Comparative study of the cooling of a hot temperature surface using sprays and liquid jets. International Journal of Heat and Mass Transfer, 81: 889-900. https://doi.org/10.1016/j.ijheatmasstransfer.2014.11.018

[9] Xu, H., Si, C., Shao, S., Tian, C. (2014). Experimental investigation on heat transfer of spray cooling with isobutane (R600a). International Journal of Thermal
Sciences,

86:

21-27.

https://doi.org/10.1016/j.ijthermalsci.2014.06.025

[10] Yang, J., Chow, L.C., Pais, M.R. (1996). Nucleate boiling heat transfer in spray cooling. Journal of Heat Transfer, 118(3): https://doi.org/10.1115/1.2822684

[11] Rini, D.P., Chen, R.H., Chow, L.C. (2002). Bubble behavior and nucleate boiling heat transfer in saturated FC-72 spray cooling. J. Heat. Transf., 124(1): 63-72. https://doi.org/10.1115/1.1418365

[12] Horacek, B., Kiger, K.T., Kim, J. (2005). Single nozzle spray cooling heat transfer mechanisms. International Journal of Heat and Mass Transfer, 48(8): 1425-1438. https://doi.org/10.1016/j.ijheatmasstransfer.2004.10.026

[13] Pereira, R.H., Braga, S.L., Parise, J.A.R. (2002). Comparing single phase heat transfer to arrays of impinging jets and sprays. International Mechanical Engineering Congress and Exposition, 351-358. https://doi.org/10.1115/IMECE2002-32531

[14] Sleiti, A.K., Kapat, J.S. (2006). An experimental investigation of liquid jet impingement and single-phase spray cooling using polyalphaolefin. Experimental Heat Transfer, $\quad 19(2)$ : https://doi.org/10.1080/08916150500479349

149-163.

15] Karwa, N., Kale, S.R., Subbarao, P.M.V. (2007). Experimental study of non-boiling heat transfer from a horizontal surface by water sprays. Experimental Thermal and Fluid Science, 32(2): 571-579. https://doi.org/10.1016/j.expthermflusci.2007.06.007

[16] Oliphant, K., Webb, B.W., McQuay, M.Q. (1998). An experimental comparison of liquid jet array and spray impingement cooling in the non-boiling regime. Experimental Thermal and Fluid Science, 18(1): 1-10. https://doi.org/10.1016/S0894-1777(98)10013-4

[17] Fabbri, M., Jiang, S.J., Dhir, V.K. (2005). A comparative study of cooling of high power density electronics using sprays and microjets. Journal of Heat Transfer - Trans. ASME, $127(1)$ : 38-48. https://doi.org/10.1115/1.1804205

[18] Mzad, H., Khelif, R. (2016). Effect of spraying pressure on spray cooling enhancement of beryllium-copper alloy plate. IX International Conference on Computational Heat and Mass Transfer, ICCHMT2016, Procedia Engineering, 157: 106-113. https://doi.org/10.1016/j.proeng.2016.08.344

[19] Ali, K., Amna, R., Usman, M., Malik, M.I., Kim, K. (2019). An investigation of the influence of surface roughness, water quality and nozzle on spray cooling of Aluminum alloy 6082. Thermal Science and Engineering Progress, $\quad 10$ : 280-286. https://doi.org/10.1016/j.tsep.2019.01.016

\section{NOMENCLATURE}

$\begin{array}{lc}\mathrm{C}_{\mathrm{p}} & \text { Specific heat }(\mathrm{J} / \mathrm{kg} \cdot \mathrm{K}) \\ \mathrm{H} & \text { Space between nozzle and plate }(\mathrm{mm}) \\ \mathrm{h}_{\mathrm{c}} & \text { Convective coefficient of heat transfer }\left(\mathrm{W} / \mathrm{m}^{2} \cdot \mathrm{K}\right) \\ \mathrm{LDT} & \text { Leidenfrost temperature } \\ \dot{\mathrm{q}}_{\min } & \text { Minimum heat flux }\left(\mathrm{MW} / \mathrm{m}^{2}\right) \\ \dot{\mathrm{q}}_{\max } & \text { Maximum heat flux }\left(\mathrm{MW} / \mathrm{m}^{2}\right) \\ \mathrm{s} & \text { Material thickness }(\mathrm{mm}) \\ \theta_{\mathrm{w}} & \text { Temperature of water }\left({ }^{\circ} \mathrm{C}\right) \\ \theta_{\mathrm{o}} & \text { Temperature of hot material }\left({ }^{\circ} \mathrm{C}\right)\end{array}$

